Check for updates

The BMJ

Cite this as: $B M J 2020 ; 369: \mathrm{m} 2635$ http://dx.doi.org/10.1136/bmj.m2635 Published: 30 June 2020

\section{Covid-19: Leicester placed under lockdown after spike in cases and hospital admissions}

\author{
Elisabeth Mahase
}

Leicester, a city in England's East Midlands, has been placed under local lockdown measures because of a rising number of covid-19 cases, the government has announced.

Speaking in the House of Commons on 29 June, health secretary Matt Hancock said that the area accounted for around $10 \%$ of all positive cases in the country over the past week and that the seven day infection rate in the area was 135 cases per 100 ooo people, three times higher than in the next highest city. Meanwhile, admissions to hospital are between six and 10 per day, compared with around one a day at other trusts.

As such, the UK government and local leaders decided that further measures were needed to tackle the outbreak, including an extension of the lockdown rules in the city of Leicester and the surrounding urban area for at least two weeks and delaying the relaxation of measures for shielding patients.

Nick Rushton, leader of Leicestershire County Council, said, "This is the first localised lockdown on this scale, and undoubtedly there will be issues to iron out. I understand this is disappointing news for residents, parents of schoolchildren, and businesses when most of the country is opening back up but it's crucial that people follow the latest advice."

Hancock said that an extra four mobile testing units alongside extra capacity at the regional test site, more home testing kits, and extra public health capacity have been provided in Leicester in the past two weeks. But despite this, more action is needed.

"Given the growing outbreak in Leicester, we cannot recommend that the easing of the national lockdown, set to take place on the 4 July, happens in Leicester," he announced. "We have decided that from tomorrow [Wednesday] non-essential retail will have to close. And, as children have been particularly impacted by this outbreak, schools will also need to close from Thursday, staying open for vulnerable children and children of critical workers as they did throughout.

"Unfortunately, the clinical advice is that the relaxation of shielding measures due on the 6 July cannot now take place in Leicester. We recommend to people in Leicester, stay at home as much as you can, and we recommend against all but essential travel to, from, and within Leicester ... We will review whether we can release any measures in 2 weeks' time."

The health secretary also announced additional testing capacity in the area, calling on anyone with symptoms to come forward, and extra funding for the local council to "enhance their communications."

"Through the councils, we will ensure support is available for those who have to self-isolate. We will work with the workplaces that have seen clusters of cases to implement more stringently the covid-secure guidelines," he added.

Addressing whether the number of cases is only high in Leicester because of increased testing, Hancock said that the proportion of people testing positive out of all those tested has not dropped, as would have been expected. "That proportion has remained static, which is why we are specifically concerned about Leicester," he said.

But Sheila Bird, former programme leader at the MRC Biostatistics Unit at the University of Cambridge, has called for more transparency over what triggers such an alert. She said, "Some city always has to have the highest percentage of swab positives per million of population in a particular week. The question is whether that highest percentage is higher than the top percentage should be? Extreme value distributions are tricky beasts and need serious statistical back-up. League tables always need qualification by measures of uncertainty.

“Transparency, weekly, about a) swab test rates per million of population, b) swab positive rate per 100 tested, and c) swab test positives per million of population (each with uncertainty) is essential-not only for Leicester but for comparator cities-for the public and professionals to be confident about how alerts will be triggered as England emerges from lockdown." 